\title{
EL CASO LA POLAR. LOS DESAFÍOS DE RESGUARDAR
} LA FE PÚBLICA

\author{
BERnARdo Navarrete YáŃEZ \\ Universidad de Santiago de Chile \\ bernardo.navarrete@usach.cl
}

El caso de la multitienda "La Polar", mostró los problemas que tienen las instituciones regulatorias y fiscalizadoras en Chile, dadas sus escasas atribuciones, y el rol de las empresas auditoras y agencias acreditadoras de riesgo que pusieron en cuestión sus reputaciones al no detectar las irregularidades que por ańos se estaban llevando a cabo. El impacto en la opinión pública generó cambios que de otra mera difícilmente se podrían haber realizado en el mercado del retail.

Palabras: La Polar, regulación, fiscalización, retail.

\section{THE CASE LA POLAR. THE CHALlENGES OF PROTECTING THE PUBLIC TRUST}

The case of the department store "La Polar" showed problems with regulatory and supervisory institutions in Chile, given its limited powers and the auditing firms and accrediting agencies risk their reputations called into question not detect irregularities for years they were conducting. The impact on public opinion led to changes that otherwise simply could hardly have made in the retail market.

Keywords: Polar, regulation, oversight, retail. 


\section{INTRODUCCIÓN}

El caso La Polar muestra que todas las instituciones llamadas a enfrentar estas situaciones fallaron, y fue un abogado, Andrés Sepúlveda Jiménez, del bufete de abogados Gutiérrez y Silva, quien el 3 de junio 2011 realizó una presentación a la Superintendencia de Valores y Seguros (SVS), informando de los movimientos dudosos de la empresa La Polar mediante una serie de consultas a su cartera crediticia, remitiéndole idéntico documento a la empresa. Cinco días después (8 de junio) llegaron a la SVS el presidente y vicepresidente del directorio de las empresas La Polar, dando a conocer que la cartera aludida en el informe se movía en disconformidad a lo que plantea el directorio y que era necesario hacer prohibiciones en la multidienda.

La multitienda "La Polar", cuyo eslogan "llegar y llevar" la hicieron parte de nuestro acervo cultural, nos planteó nuevamente el problema de la confianza hacia las instituciones en Chile y la incertidumbre sobre quién nos protege de las arbitrariedades. ¿Cómo es posible que en una multitienda un hervidor de agua, en sucesivas repactaciones unilaterales, termine costando 1 millón de pesos? ¿Cómo fue posible que cuatrocientos dieciocho mil clientes fueran víctimas de repactaciones forzosas?, y muy especialmente, ¿por qué las instituciones llamadas a controlar y regular esta actividad fallaron?

Paramio (1996) ha planteado que bajo el común denominador de la incertidumbre, es posible analizar muchos de los cambios producidos en nuestras sociedades en años recientes, más específicamente, desde los inicios de la globalización de los mercados de capitales que generan nuevas reglas del juego en la economía mundial. Y la incertidumbre económica se terminó traduciendo en incertidumbre política.

En palabras de Beck, se transitó desde la "solidaridad de las necesidades", que necesitaba instituciones que se hicieran cargo de apoyar a los individuos, a la "solidaridad del miedo", que no tiene instituciones muy definidas para protegerlos (Huneeus, 1998). En este escenario, el malestar que va surgiendo es un fenómeno que se ha instalado en la opinión pública y que se expresa en una falta de alternativas. Esto se refleja, a su vez, en la erosión de los mapas cognitivos, generando y acentuando la distancia entre lo político, la experiencia 
cotidiana del ciudadano de a pie, y la política institucionalizada. No implica una protesta activa; representa, más bien, la reacción frente a una realidad que aparece ininteligible y sustraída a la voluntad de los ciudadanos. Hay una disonancia entre esa percepción de la realidad social y lo que se espera de la política, pero las cosas simplemente acontecen, y en ausencia de claves interpretativas que permitan verbalizar la incongruencia, sólo queda un malestar vago y mudo (Lechner, 1993) y una angustia por el presente y el futuro (Tironi, 1998); esto último en manos de quienes ejercen cargos políticos. Pero parece obvio que la influencia política que ejercen estas elites está desproporcionada respecto a su capacidad de resolver problemas en la actual institucionalidad y, por otro lado, se les critica porque están diseñando un marco legal donde ejercerían políticas en su propio beneficio, lo que algunos han llamado Political Cronyism ("Amiguismo Político"), fomentando la persistencia de una mayor desigualdad entre algunos y el todo. En general, el amiguismo se define como la parcialidad por los amigos de muchos años, mediante el nombramiento en puestos de autoridad, independientemente de sus calificaciones (Zudenkovay, 2011).

Las preguntas que surgen del caso en cuestión son 3: ¿Existe un marco regulatorio que fiscalice las acciones administrativas y económicas de los Retails? Si es así, ¿cómo funcionan? y, finalmente ¿por qué en esta situación no funcionaron? En respuesta a la primera pregunta, efectivamente existen marcos regulatorios que fiscalizan los retails. La Ley No 18.045 de Mercado de Valores se publicó en el Diario Oficial del 22 de octubre de 1981, cuyas rectificaciones se publicaron en el Diario Oficial del 31 de octubre del mismo año, con algunas modificaciones durante el transcurso del tiempo. La última fue con el Artículo $5^{\circ}$ de la Ley $\mathrm{N}^{\circ}$ 20.552, publicada en el Diario Oficial del 17 de diciembre de 2011 a causa del caso La Polar. Ahora bien, respecto a cómo funcionan, la respuesta es por la vía de la fiscalización constante de las entidades a cargo de la supervisión. A modo de ejemplo, el Servicio Nacional del Consumidor (SERNAC), entre los años 2006 y 2008 para el caso en estudio, realizó sólo una fiscalización al año.

Por último, la tercera pregunta se responde asumiendo que la regulación falla cuando no es útil para los fines que fue creada. En el caso de la normativa financiera y de valores, lo que se busca es resguardar la fe pública y la estabilidad del mercado en cuestión. ¿Cuáles habrían sido las fallas al respecto? 
Una de ellas dice relación con la prevención de los conflictos de interés, en este caso, debido a que los ejecutivos habrían alterado estados financieros para obtener ganancias relevantes por la compra y venta de acciones de la empresa, en un escenario donde la revelación de la información ha generado importantes asimetrías y por un tiempo prolongado. Dentro de este contexto, entro a exponer el caso La Polar partiendo del concepto regulación y de una descripción de las empresas auditoras y agencias acreditadoras de riesgo. Seguidamente, abordo los cambios que generó el caso La Polar en la institucionalidad regulatoria chilena, para -desde este caso-, avanzar en la creación de una agencia de evaluación de políticas públicas.

\section{LA REGULACIÓN EN LA TEORÍA POLÍTICA Y LAS LECCIONES INTERNACIONALES} DE LAS EMPRESAS AUDITORAS Y AGENCIAS ACREDITADORAS DE RIESGO

La regulación como concepto apunta a la adopción de "medidas adecuadas para producir consecuencias tangibles, previstas y deseadas en una situación real seleccionada por el regulador, de tal manera que dicha situación, denominada A en un momento hipotético anterior a la aplicación de las medidas, tienda a transformarse, por efecto de las mismas, en la diferente situación A', dotada de nuevas características gratas, y/o carente de características anteriores no gratas". En consecuencia, el Estado al regular "escoge y pondera bienes e intereses para que sean objeto de tutela; identifica y previene riesgos, y para ello diseña, dota de sanciones, adopta y aplica reglas de conducta dirigidas a los consocios" (Majone y Spina, 1993: 213-214).

La regulación en el contexto donde la estamos analizando, lleva al debate sobre la autonomía de los órganos reguladores, la legitimidad adquirida y la eficiencia con la que operan (Chiapa, 2009), así como también la economía del comportamiento, conocida como "economía de estúpidos", que tiene como objetivo principal estudiar por qué fallan las personas a la hora de pensar o actuar racionalmente sobre lo que -en teoría-, es de su propio interés racional; esto supuestamente por carecer de autodisciplina (Benkler, 2010). Parafraseando la ética protestante reseñada por Max Weber, ésta nunca es ni universal ni absoluta y debe, por tanto, ser sostenida por el sistema político. 
Si la ética la llevamos a reglas, debemos asumir que la mayoría de éstas son estándares voluntarios más que directrices obligatorias (Ahme y Brunsson, 2005). Si el sistema político debe asumir el debate sobre la naturaleza y efectos de la regulación, las reglas deben resolverse en términos de si la regulación que pretende aplicar es para que la competencia funcione mejor para los consumidores, o para evitar consecuencias negativas para los ciudadanos (Parker y Pearson, 2005). Cualquiera de las dos vías, puede -y en buena medida debe-, ser vista desde la teoría del principal-agente, donde la relación contractual entre los reguladores y las empresas reguladas debe asumir que el principal es la población y el agente el gobierno.

El problema es que el principal es un consumidor poco atento a las restricciones que establecen las empresas y el agente deja de proteger a este descuidado ciudadano. Protegerlo es asumir que la regulación es una instancia neutral superior, "con poderes normativos y autoritarios, de la que se espera un empleo de dichos poderes eficaz y públicamente justificable, ya que lo rigen buenas razones"; pero también "la urgencia, la dificultad técnica y la continua redefinición de algunos de los problemas que son objeto de la regulación parecen sugerir que se recurra a instrumentos, procedimientos y organismos".

En Chile, la regulación financiera, donde se incluyen las tarjetas de casas comerciales o multitiendas, ha "estado enfocada en preservar la estabilidad o solvencia del estado financiero más que en el resguardo de los derechos del consumidor", por ello nuestra regulación se califica de "prudencial" ya que busca que los bancos no entren en crisis de liquidez, pero no resguarda los derechos del cliente y el llamado a realizarlo, el Servicio Nacional del Consumidor (SERNAC) tiene "escasas" atribuciones (González, 2011: 169). De hecho la discusión sobre la normas del SERNAC demoró siete años (1990-1997) ya que la preocupación por generar "una industria del reclamo" terminó por establecer "una industria del abuso" (Roa, 2011: 147).

El escándalo por el funcionamiento de las regulaciones de los Retails en Chile, más específicamente por el caso La Polar, el cual se mostró como un negocio que iba en alza y aseguraba rentabilidad, llevó a una importante cantidad de accionistas minoritarios a confiar en obtener algún tipo de utilidad con esta inversión, esto en parte porque las empresas auditoras, las agencias acreditadoras 
de riesgo y corredoras de bolsa así lo sugerían o daban las señales para invertir en los títulos de la multitienda.

\section{I LAS EMPRESAS AUDITORAS Y AGENCIAS ACREDITADORAS DE RIESGO. El BIG4.}

El Big4 agrupa a las cuatro empresas más grandes de auditoría a nivel internacional: KPMG, Deloitte Touche Tohmatsu, Price Waterhouse Coopers y Ernst \& Young. La alta concentración del mercado de auditoría ha sido explicada por sus comportamientos estratégicos para especializarse por sector de actividad de las empresas auditadas y por tamaño de dichas empresas; asimismo, por la prestación del servicio de auditoría a precios más competitivos debido a la presencia de economías de escala basadas en el tamaño de las firmas de auditoría, y por el uso de metodologías estructuradas de planificación y ejecución de las auditorías (Toscano y García, 2011). El tamaño marca un punto de inflexión, porque se está demostrando que cuando una auditora cuenta con las oficinas más grandes en un país o ciudad, proporciona auditorías de calidad superior (Jere y Yu, 2009).

Estas empresas, en los "primeros cuatro años del siglo XXI han admitido haber sido negligentes en el desempeño de sus servicios o han pagado multas de elevada cuantía sin admisión alguna de culpa" (Heclo, 2010: 34-35). Esto ha llevado a que hoy se esté ofreciendo una mayor calidad en las auditorías, con el fin de proteger la reputación de la marca de la empresa y evitar juicios costosos (Khurana y Raman, 2004). Aquí entramos al "precio de las reputaciones" (Jere, Reichelt y Wang, 2005), que en el caso La Polar fue significativo no tanto para desaparecer o dejar de funcionar, ya que -como dice Heclo- puedo pagar multas pero no admitir culpas.

\section{Los Cambios QUe generó el Caso La Polar en la institucionalidad REGULATORIA.}

En Chile, el mercado está "altamente concentrado", es "pequeño" y tiende a la "competencia oligopólica" (Estrategia, 2012: 1). El trabajo de Patrick Rey, de 
la Universidad de Toulouse, va en esta línea argumental: "las conductas más comunes de restricciones verticales en Chile son la fijación de precios de reventa, acuerdos de exclusividad, descuentos condicionales, ventas atadas, asignación de zonas geográficas, discriminación arbitraria, cláusulas abusivas", las que pueden -además-, ser facilitadoras de colusión y excluir a competidores (Estrategia, 2012: 1). En este escenario, y a efecto de exponer los cambios en las atribuciones regulatorias, muestro el cuadro $\mathrm{N}^{\circ} 1$, el cual presenta los cambios que generó en las instituciones públicas el caso de La Polar.

\section{Cuadro $\mathrm{N}^{\circ} 1$ : Los cambios que generó en las instituciones públicas el caso de La Polar}

\begin{tabular}{|c|c|c|}
\hline Organismos públicos & Antes & Después \\
\hline $\begin{array}{l}\text { Superintendencia } \\
\text { de Valores y Seguros } \\
\text { (SVS) }\end{array}$ & $\begin{array}{l}\text { Contribuir al desarrollo } \\
\text { de los mercados de } \\
\text { valores y seguros } \\
\text { mediante una regulación } \\
\text { y una fiscalización } \\
\text { eficientes, que faciliten } \\
\text { la participación de los } \\
\text { agentes de mercado y que } \\
\text { promuevan el cuidado } \\
\text { de la fe pública y el } \\
\text { resguardo de los derechos } \\
\text { de inversionistas y } \\
\text { asegurados. }\end{array}$ & $\begin{array}{l}\text { Refuerzanlaimportancia delaautorregulación } \\
\text { en las corporativas responsables, a través de la } \\
\text { norma general } 341 \text {. }\end{array}$ \\
\hline $\begin{array}{lr}\text { Servicio } & \text { Nacional } \\
\text { del } & \text { Consumidor } \\
(\text { SERNAC) } & \end{array}$ & & $\begin{array}{l}\text { SERNAC Financiero: creado por la ley } \\
\mathrm{N}^{\circ} 20.555 \text {, con la función de complementar } \\
\text { la Ley de Protección al Consumidor; empezó } \\
\text { a regir el } 5 \text { de junio del } 2012 \text {. A partir de esa } \\
\text { fecha, el consumidor tiene el derecho a exigir } \\
\text { claridad en el servicio que está contratando, } \\
\text { información simple y transparente por escrito. }\end{array}$ \\
\hline
\end{tabular}




\begin{tabular}{|c|c|c|}
\hline Organismos públicos & Antes & Después \\
\hline $\begin{array}{l}\text { Superintendencia de } \\
\text { Bancos e Instituciones } \\
\text { Financieras (SBIF) }\end{array}$ & $\begin{array}{l}\text { Circular No 17: Establecía } \\
\text { que si una institución } \\
\text { aumentaba el costo de } \\
\text { las tarjetas, su solo uso se } \\
\text { entendía como aceptación } \\
\text { por parte del cliente. }\end{array}$ & $\begin{array}{l}\text { Circular No40, que reemplaza la Circular No } \\
\text { 17: } \\
\text { 1-Exige al retail financiero la entrega mensual } \\
\text { de información sobre créditos y cuentas por } \\
\text { cobrar a los titulares de tarjetas y líneas de } \\
\text { créditos disponible. } \\
\text { 2-Eleva las exigencias mínimas de capital } \\
\text { y liquidez para emisores y operadores de } \\
\text { tarjetas. } \\
\text { El } 20 \text { de abril de } 2013 \text { el Banco Central } \\
\text { (BC) y la Superintendencia de Bancos e } \\
\text { Instituciones Financieras (SBIF) publicaron } \\
\text { la nueva regulación que eleva las exigencias } \\
\text { regulatorias para emisores y operadores de } \\
\text { tarjetas de crédito y que, a su vez, amplía } \\
\text { el marco regulatorio de fiscalización } \\
\text { incorporando a las tarjetas del retail. A través } \\
\text { de la Circular } 17 \text { la Superintendencia de } \\
\text { Bancos e Instituciones Financieras (SBIF) } \\
\text { podrá realizar, desde el } 1 \text { de enero de 2014, } \\
\text { "Supervisión in situ", lo que se traduce en que } \\
\text { podrá "requerir y examinar la información } \\
\text { que estime necesaria, realizar supervisión } \\
\text { en terreno, fijar normas contables, además } \\
\text { de contar con la facultad de imponer } \\
\text { amonestaciones y multas". }\end{array}$ \\
\hline Cámara Diputados & & $\begin{array}{l}\text { Se crea la Comisión Investigadora sobre } \\
\text { el caso La Polar, que está evaluando las } \\
\text { responsabilidades de las autoridades } \\
\text { fiscalizadoras del Sernac y del Banco Central, } \\
\text { quienes explicaron los antecedentes que ellos } \\
\text { manejaban antes de que esto saliera a la luz y } \\
\text { la demanda colectiva realizada por el Sernac } \\
\text { ante tribunales. } \\
\text { El diputado Felipe Harboe (PPD) presentó un } \\
\text { proyecto de ley el año } 2011 \text { para fiscalizar las } \\
\text { casas comerciales, con el objetivo de evitar lo } \\
\text { ocurrido con La Polar. Este proyecto contempla } \\
\text { las cotizaciones variables e ir al rescate } \\
\text { financiero y fiscalizar las empresas auditoras, } \\
\text { evitando que estas mismas tengan intereses } \\
\text { asociados e involucren contratos por sí mismas; } \\
\text { la Superintendencia de Valores y Seguros (SVS) } \\
\text { debe estar facultada para contratar y así evitar } \\
\text { relación clientelar, estableciendo un plazo } \\
\text { máximo de contrato de } 3 \text { ańos. }\end{array}$ \\
\hline
\end{tabular}




\begin{tabular}{|c|c|c|}
\hline Organismos públicos & Antes & Después \\
\hline $\begin{array}{l}\text { Contraloría General } \\
\text { de la Republica }\end{array}$ & & $\begin{array}{l}\text { La Contraloría General de la República } \\
\text { declara que las superintendencias no tienen } \\
\text { las facultades de dar órdenes a los bancos ni } \\
\text { a la clientela. }\end{array}$ \\
\hline $\begin{array}{lr}\text { Ley } \mathrm{n}^{\circ} & 18.046(1) \\
\text { Ley de } & \text { sociedades } \\
\text { anónimas } & \end{array}$ & $\begin{array}{l}\text { La persona que infrinja } \\
\text { esta ley, su reglamento } \\
\text { o, en su caso, los } \\
\text { estatutos sociales o las } \\
\text { normas que imparta } \\
\text { la Superintendencia } \\
\text { ocasionando daño a } \\
\text { otro, está obligada a } \\
\text { la indemnización de } \\
\text { perjuicios. Lo anterior es } \\
\text { sin perjuicio de las demás } \\
\text { sanciones civiles, penales } \\
\text { y administrativas que } \\
\text { correspondan } \\
\text { (TÍTULO XIV. De } \\
\text { las responsabilidades } \\
\text { y sanciones, Artículo } \\
\text { 133.1) }\end{array}$ & $\begin{array}{l}\text { Toda pérdida irrogada al patrimonio de } \\
\text { la sociedad como consecuencia de una } \\
\text { infracción a esta ley, su reglamento, los } \\
\text { estatutos sociales, las normas dictadas por } \\
\text { el directorio en conformidad a la ley o las } \\
\text { normas que imparta la Superintendencia, } \\
\text { dará derecho a un accionista o grupo de } \\
\text { accionistas que representen, a lo menos, un } \\
5 \% \text { de las acciones emitidas por la sociedad o } \\
\text { a cualquiera de los directores de la sociedad, } \\
\text { a demandar la indemnización de perjuicios a } \\
\text { quien correspondiere, en nombre y beneficio } \\
\text { de la sociedad (TíTULO XIV. De las } \\
\text { responsabilidades y sanciones) }\end{array}$ \\
\hline Banco Central & & $\begin{array}{l}\text { Cambio en la normativa que rige a los } \\
\text { emisores de créditos no-bancarios III.J.I y } \\
\text { aplicación Título } 1 \text { Ley General de Bancos. } \\
\text { Entrega más facilidades a la Superintendencia } \\
\text { de Bancos para regular y fiscalizar el retail } \\
\text { financiero. }\end{array}$ \\
\hline
\end{tabular}

Fuente: Elaboración propia en base a prensa y páginas web institucionales. 


\section{Cuadro $\mathrm{N}^{\circ}$ 2: Los cambios que generó en las instituciones privadas el caso de La Polar}

\begin{tabular}{|c|c|c|}
\hline Instituciones Privadas & 2011 & 2013 \\
\hline $\begin{array}{l}\text { Price Waterhouse Coopers } \\
\text { (PWC) } \\
\text { En junio de 2011, el } \\
\text { Directorio de La Polar } \\
\text { informa la contratación de } \\
\text { Deloitte para revisión de } \\
\text { cartera de clientes. }\end{array}$ & $\begin{array}{l}\text { Incumplimiento a lo establecido } \\
\text { en el Artículo } 248 \text {, inciso } 1^{\circ} \text { de } \\
\text { la Ley No } 18.045 \\
\text { No cumplió las instrucciones } \\
\text { de la Circular } N^{\circ} 1.441 \text { (que } \\
\text { contiene normas mínimas de } \\
\text { auditoría externa y del informe } \\
\text { con la opinión del sistema de } \\
\text { control interno para compañías } \\
\text { de seguros) } \\
\text { La normativa para las emisoras de } \\
\text { tarjetas de créditos no bancarios, } \\
\text { contempla la elaboración por } \\
\text { parte de auditores externos, } \\
\text { de reportes anuales que dan } \\
\text { cuenta del funcionamiento } \\
\text { de la empresa y que luego son } \\
\text { enviados a la SBIF }\end{array}$ & $\begin{array}{l}\text { Disminución de los precios de } \\
\text { referencia, después del caso La } \\
\text { Polar } \\
\text { Trabaja principalmente con } \\
\text { empresas que forman parte } \\
\text { del IPSA }\end{array}$ \\
\hline Ernst \& Young & $\begin{array}{l}\text { El ańo 2004, el contador auditor } \\
\text { Roberto Morales Chamorro fue } \\
\text { nombrado por la auditora Ernst } \\
\text { \& Young para encargarse de La } \\
\text { Polar. Ese año la empresa se abre } \\
\text { a la bolsa, y sus memorias de } \\
\text { los ańos } 2004 \text { y } 2005 \text { cuentan } \\
\text { con la firma del seńor Morales } \\
\text { como contador auditor de la } \\
\text { multitienda (ciperchile.cl, 2011) } \\
\text { Consultora de La Polar (PWC) } \\
\text { ahora es auditada por la Policía } \\
\text { de Investigaciones (PDI.). }\end{array}$ & $\begin{array}{l}\text { Son interrogados por informe } \\
\text { del año 2006, manteniendo } \\
\text { las sospechas de maquillar la } \\
\text { información entregada. } \\
\text { Las empresas del grupo Matte } \\
\text { y Angelini, optaron por } \\
\text { cambiar de auditora. }\end{array}$ \\
\hline
\end{tabular}

Fuente: Elaboración propia en base a prensa nacional.

\subsection{PRoyectos DE LEY}

El caso La Polar generó, como era esperable, respuestas legislativas que se tradujeron en una serie de medidas para prevenir escándalos similares y para la protección del consumidor. Estas son:

a. Consejo de Estabilidad Financiera: creado el 25 de octubre del 2011, de carácter permanente, orientado a prevenir fraudes y crisis como los de La Polar. El 
Consejo posee la facultad de solicitar información acerca de la estructura de los conglomerados financieros, de modo que exista una efectiva coordinación entre entes supervisores y reguladores. El Consejo lo integran el Ministro de Hacienda, quien lo preside, el Superintendente de Valores y Seguros, el Superintendente de Bancos e Instituciones Financieras y el Superintendente de Pensiones.

b. Proyecto de ley que perfecciona el tipo penal de estafa y tipifica el delito de administración desleal: viene a cubrir lo que el ex diputado y hoy senador, Pedro Araya, señala como vacíos legales, en donde casos como el de La Polar, que perjudicaba económicamente a sus consumidores, no eran totalmente penalizables y, por ende, existía una cierta impunidad al respecto. Actualmente el proyecto se encuentra en su primer trámite constitucional y sin urgencia.

b. Proyecto de ley sobre deuda consolidada: busca crear un sistema de información negativa (morosidades) y positiva (deudas al día) de todas las personas. Dichos datos serán administrados por un Sistema de Obligaciones Económicas (SOE), mecanismo que pedirá, almacenará y entregará la información comercial a las distribuidoras, tales como DICOM y el Boletín Comercial. El SOE será licitado por medio de la Superintendencia de Bancos e Instituciones Financieras (SBIF). El proyecto con suma urgencia se encuentra en el primer trámite constitucional, pasando de la Comisión de Economía a la Comisión de Constitución (Cámara de Diputados, 2012).

\subsection{HaCiA UNA AGENCIA DE EVALUACIÓN DE POLÍTICAS PÚBLICAS}

En agosto de 2012, el Ministro Secretario General de la Presidencia, Cristián Larroulet, planteó que se no se generarían normas regulatorias sin que previamente sean evaluadas para justificar la eficacia de su implementación. Esto llevó al Ejecutivo a proponer la creación de una agencia de evaluación de las políticas públicas (elmostrador.cl, 2012). Esta idea no es nueva; de hecho, en la administración Bachelet (2006-2010) se analizó desde el Ministerio General de la Presidencia una propuesta (Olavarría y Figueroa, 2010) y se ha mantenido en la discusión (Ferreiro, 2011).

Un segundo modelo de agencia estaría en la Oficina de protección al Consumidor Financiero, que se fundó en Estados Unidos en el 2010 como respuesta a la crisis subprime, a la cual se le entregaron facultades para dictar normas, investigar y aplicar sanciones. Un tercer modelo es el que está implementando el Reino 
Unido, que separó en dos agencias la labor regulatoria, por una parte la encargada de la regulación prudencial y de solvencia y por otra la agencia encargada de la promoción de la competencia y la protección del consumidor (González, 2011).

\section{Conclusiones}

Si bien los escándalos políticos - donde podríamos incorporar el caso La Polar- no tienen relevancia sobre el voto ciudadano y no dan lugar a una derrota electoral (Jiménez y Caínzos, 2004), en Chile sí afectaron a la coalición gobernante, ya que -como se ha sostenido-, se asoció a ésta con el abuso y el amparo del mismo. En este sentido, este caso será una lección aprendida para quienes asuman un gobierno en el futuro.

El caso La Polar tiene como efecto la generación de una serie de medidas políticas y de políticas que, sin su existencia, difícilmente habrían sido abordadas por el ejecutivo y el legislativo. La opinión pública, al expresarse mayoritariamente contra las prácticas denunciadas presionando por mayores medidas regulatorias, manifestó su baja tolerancia al abuso. El problema es que esas medidas no terminen generando un marco que sobredimensione las funciones de las agencias e instituciones que fallaron. Para el gobierno de Bachelet (2014-2018), éste debería ser uno de los debates para dar un marco de políticas que asegure el equilibrio de actores en el mercado nacional, considerando la necesaria entrada de nuevas instituciones, tal como se postula en este artículo. 


\section{BiBLIOGRAFÍA}

Ahme, Coran y Nils Brunsson (2005). "La regulación suave desde una perspectiva organizacional. Gestión y Política Pública”. Gestión y Política Pública, Vol. XIV, Nº 3, pp. 527-555.

Benkler, Yochai (2010). "Del desespero de Greenspan a la esperanza de Obama: Las bases científicas de la cooperación como principios de regulación”. Revista de Economía Institucional, vol. 12 , No 23 , pp. 29-53.

Chiapa, Everardo (2009). Recensión al libro Nuevas fronteras de la regulación: Transformación y diseño institucional, de Jorge Culebro (ed.), México, UAM Cuajimalpa / Juan Pablos Editor, 297 pp.

Coller, X. (2005). Estudios de Casos. Cuadernos Metodológicos $N^{\circ} 30$. España: Centro de Investigaciones Sociológicas.

Ferreiro, Alejandro (2011). “Agencia de calidad para la evaluación de las políticas públicas”. En Andrea Peroni (ed.) Perspectivas de la evaluación publica en Chile. Núcleo de Evaluación de Políticas Públicas. Departamento de Sociología. Universidad de Chile.

González, Aldo (2011). "Nueva institucionalidad para la protección del consumidor financiero", en Ricardo Lagos y Oscar Landerretche (editores). El Chile que se viene. Ideas, miradas, perspectivas y sueños para el 2030. Santiago: Editorial Catalonia.

Heclo, Hugh (2010). Pensar institucionalmente. Barcelona: Editorial Paidós.

Huneeus, Carlos (1998). "Malestar y desencanto en Chile. Legados del autoritarismo y costos de la transición”. Papeles de trabajo No 63. Santiago: Programa de Estudios Prospectivos PEP. Corporación Tiempo 2000.

Jere R. Francis y Michael D. Yu (2009). "Big 4 Office Size and Audit Quality”. The Accounting Review Vol. 84, N5, pp. 1521-1552.

Jere R. Francis; Kenneth Reichelt y Dechun Wang (2005). "The Pricing of National and CitySpecific Reputations for Industry Expertise in the U.S.”. Audit Market vol. 80, № 1, pp. 113-136.

Jiménez, Fernando y Miguel Caínzos (2004). “La repercusión electoral de los escándalos políticos. Alcance y condiciones". Revista Española de Ciencia Política. N 10, pp. 141-170.

Khurana, Inder y K. K. Raman (2004). "Litigation Risk and the Financial Reporting Credibility of Big 4 versus Non-Big 4 Audits: Evidence from Anglo-American Countries". The Accounting Review Vol. 79, N² 2, pp. 473-495.

Lechner, Norbert (1993). “Los nuevos perfiles de la política. Un bosquejo”. Serie Estudios Políticos No 31, FLACSO, Programa Chile. 
Majone, Giandomenico y Antonio la Spina (1993). "El Estado regulador". Gestión y Política Pública, vol. 11, N², pp. 197-261.

Olavarría, Mauricio y Verónica Figueroa (2010). Una Agencia de evaluación de políticas públicas para Chile: lecciones de la historia y de la experiencia internacional. Santiago: Editorial Universitaria.

Paramio, Ludolfo (1996). "La sociedad desconfiada”. Revista Leviatan. № 66.

Parker, Martin y Gordon Pearson (2005). "Capitalism and Its Regulation: A Dialogue on Business and Ethics”. Journal of Business Ethics Vol. 60, N 1, pp. 91-101.

Roa, José (2011). "La revolución de los derechos de los consumidores”. En Ricardo Lagos y Oscar Landerretche (editores). El Chile que se viene. Ideas, miradas, perspectivas y sueños para el 2030. Santiago: Editorial Catalonia.

Toscano, Juan y María García (2011). "Estrategias de las cuatro grandes firmas de auditoría en México”. Revista Europea de Dirección y Economía de la Empresa, vol. 20, Nº pp. 89-104.

\section{ARTÍCULOS DE PRENSA}

CIPER (2011). "Nueva pista del fraude: El auditor externo de La Polar que se convirtió en asesor clave de gerencia". 28 de noviembre. http://ciperchile.cl/2011/11/28/nueva-pista-del-fraude-el-auditor-externo-de-la-polar-que-se-convirtio-en-asesor-clave-de-gerencia/

Estrategia (2012). “Estudio de FNE Reconoce Competencia Oligopólica en Chile”, p. 1 Portada. 14 noviembre.

El Mostrador (2012). "Gobierno estudia creación de organismo coordinador de políticas regulatorias”. http://www.elmostrador.cl/ahora/2012/08/09/gobierno-estudia-creacion-de-organismo-coordinador-de-politicas-regulatorias/

Tironi, Eugenio (1998). Revista Qué Pasa. 11 de abril. 